\title{
Editorial: Metal Hydride-Based Energy Storage and Conversion Materials
}

\author{
Yongfeng $\mathrm{Liu}^{1 *}$, Hai-Wen $\mathrm{Li}^{2 *}$ and Zhenguo Huang ${ }^{3 *}$ \\ ${ }^{1}$ State Key Laboratory of Silicon Materials, School of Materials Science and Engineering, Zhejiang University, Hangzhou, \\ China, ${ }^{2}$ Platform of Inter/Transdisciplinary Energy Research, International Research Center for Hydrogen Energy, International \\ Institute for Carbon-Neutral Energy Research, Kyushu University, Fukuoka, Japan, ${ }^{3}$ School of Civil \& Environmental \\ Engineering, University of Technology Sydney, Ultimo, NSW, Australia
}

Keywords: metal hydrides, complex hydrides, energy storage, hydrogen storage, catalysis

\section{Editorial on the Research Topic}

\section{Metal Hydride-Based Energy Storage and Conversion Materials}

Energy storage and conversion materials are of critical importance in the development and utilization of new renewable clean energies (Li et al., 2016). Hydrogen, as an ideal energy carrier that can be transportable, storable, and convertible, has the potential to become a solution to energy security, resource availability, and environmental compatibility (Martin et al., 2020). Storing hydrogen in a safe, effective and economic way, however, is a great challenge in the development of a hydrogen-based economy, because of the extremely low volumetric density $\left(0.0899 \mathrm{~kg} \mathrm{~m}^{-3}\right)$ at ambient condition (Schlapbach and Züttel, 2001). Compared to pressurizing gaseous or liquefying hydrogen, storing hydrogen in metal hydride has definite advantages in terms of gravimetric and volumetric density, safety, and energy efficiency, for both mobile and stationary applications (Wu, 2008; He et al., 2019; Ouyang et al., 2020). Criteria developed by the US Department of Energy (DOE) for onboard hydrogen storage for light-duty fuel cell vehicles include $6.5 \mathrm{wt} \%$ of systematic gravimetric density and $50 \mathrm{~kg} \mathrm{H}_{2} \mathrm{~m}^{-3}$ of volumetric density along with other stringent properties such as operating temperature $\left(<85^{\circ} \mathrm{C}\right)$, extended cycle-life, fast kinetics, safety, and cost. Therefore, in the last decade tremendous efforts have been devoted to the research and development of light metal hydrides, including $\mathrm{MgH}_{2}$, alanates, borohydrides, amides/imides, which hold sufficiently high hydrogen capacity (Orimo et al., 2007; Hansen et al., 2016; Yu et al., 2017; Liu et al., 2018; Schneemann et al., 2018; Zhou et al., 2019; Hirscher et al., 2020).

This special issue of Metal Hydride-Based Energy Storage and Conversion Materials is focused on the synthesis, catalyst development, and nano-structuring of light metal hydrides $\left(\mathrm{MgH}_{2}, \mathrm{AlH}_{3}\right.$, $\mathrm{NaAlH}_{4}$, and $\mathrm{LiBH}_{4}$ ) as hydrogen storage media. The eight contributions to this special issue highlight that metal hydrides are promising candidates for high density hydrogen storage.

Catalysts prove effective in reducing the reaction energy barriers for hydrogen absorption and desorption in Mg-based materials. Ding et al. report the catalytic activity of Co-Ni nanocatalyst with different compositions and morphology for hydrogen storage reaction of $\mathrm{MgH}_{2}$. The partial replacement of $\mathrm{Ni}$ by $\mathrm{Co}$ induced a change in the morphology from spherical to platelike, which is found to be less effective toward catalytic activity, presumably due to reduced surface contact. Zeng et al. prepared $\mathrm{Ni}$ and $\mathrm{TiO}_{2}$ co-anchored on reduced graphene oxide [(Ni$\mathrm{TiO}_{2}$ )@rGO], which showed superior catalytic effects on the hydrogen desorption, as evidenced by the release of $1.47 \mathrm{wt} \% \mathrm{H}_{2}$ by $\mathrm{MgH}_{2}$ within $120 \mathrm{~min}$ at $225^{\circ} \mathrm{C}$. Wang and Deng ameliorated the performance of $\mathrm{MgH}_{2}$ by using a core-shell Co@N-rich carbon (CoNC) based catalyst. In their work, the $\mathrm{MgH}_{2}-5 \mathrm{wt} \%$ CoNCo composites released up to $6.58 \mathrm{wt} \%$ of $\mathrm{H}_{2}$ in $5 \mathrm{~min}$ at $325^{\circ} \mathrm{C}$. 
Liu Y. et al. present that $\mathrm{Pd}$-decorated $\mathrm{Mg}$ nanoparticles, ranging from 40 to $70 \mathrm{~nm}$, started releasing $\mathrm{H}_{2}$ at $216.8^{\circ} \mathrm{C}$ and absorbed $3.0 \mathrm{wt} \%$ hydrogen in $2 \mathrm{~h}$ at $50^{\circ} \mathrm{C}$. In addition, $\mathrm{Wu}$ et al. investigated the effects of $\mathrm{CeH}_{2.73} / \mathrm{CeO}_{2}$ composites on the desorption properties of $\mathrm{Mg}_{2} \mathrm{NiH}_{4}$. The onset dehydrogenation temperature and activation energy of $\mathrm{Mg}_{2} \mathrm{NiH}_{4}$ were largely reduced when $\mathrm{CeH}_{2.73} / \mathrm{CeO}_{2}$ composite with the same molar ratio of hydride and oxide were used as a catalyst.

Zhang et al. reported highly stable catalytic activity of amorphous-carbon-supported $\mathrm{TiB}_{2}$ nanoparticles with sizes of 2-4 nm (nano- $\mathrm{TiB}_{2} @ \mathrm{C}$ ) for hydrogen storage in $\mathrm{NaAlH}_{4}$. They observed $5.04 \mathrm{wt} \%$ of hydrogen released at $140^{\circ} \mathrm{C}$ within $60 \mathrm{~min}$, and complete hydrogenation at $100^{\circ} \mathrm{C}$ within 25 min under a hydrogen pressure of 100 bar. The stable catalytic function was closely related to the in-situ formed $\mathrm{Ti}-\mathrm{Al}$ alloy, which facilitated the dissociation and formation of $\mathrm{H}-\mathrm{H}$ and $\mathrm{Al}-\mathrm{H}$ bonds, respectively. Liu $\mathrm{H}$. et al. reported wet chemical synthesis of non-solvated rod-like $\alpha^{\prime}-\mathrm{AlH}_{3}$, which releases $7.7 \mathrm{wt} \% \mathrm{H}_{2}$ at $120-200^{\circ} \mathrm{C}$. In addition, Fan et al. synthesized a flexible, waterresistant, and air-stable hydrogen storage material (PMMA$\mathrm{LiBH}_{4} / \mathrm{GMF}$ ), which consists of $\mathrm{LiBH}_{4}$ nanoparticles confined by poly (methylmethacrylate) (PMMA) and reduced graphene oxide (rGO) modified melamine foam (GMF). Interestingly, the onset dehydrogenation temperature of $\mathrm{PMMA}^{-\mathrm{LiBH}_{4} / \mathrm{GMF}}$ was reduced to $94^{\circ} \mathrm{C}$ and desorbed $2.9 \mathrm{wt} \%$ hydrogen within $25 \mathrm{~min}$ at $250^{\circ} \mathrm{C}$. This simple preparation process sheds light

\section{REFERENCES}

Hansen, B. R. S., Paskevicius, M., Li, H.-W., Akiba, E., and Jensen, T. R. (2016). Metal boranes: progress and applications. Coord. Chem. Rev. 323, 60-70. doi: 10.1016/j.ccr.2015.12.003

He, T., Cao, H. J., and Chen, P. (2019). Complex hydrides for energy storage, conversion, and utilization. Adv. Mater. 31:1902757. doi: 10.1002/adma.201902757

Hirscher, M., Yartys, V. A., Baricco, M., von Colbe, J. B., Blanchard, D., Bowman, R. C., et al. (2020). Materials for hydrogen-based energy storage - past, recent progress and future outlook. J. Alloys Compd. 827:153548. doi: 10.1016/j.jallcom.2019.153548

Li, W., Liu, J., and Zhao, D. Y. (2016). Mesoporous materials for energy conversion and storage devices. Nat. Rev. Mater. 1:16023. doi: 10.1038/natrevmats.2016.23

Liu, Y. F., Ren, Z. H., Zhang, X., Jian, N., Yang, Y. X., Gao, M. X., et al. (2018). Development of catalyst-enhanced sodium alanate as an advanced hydrogen-storage material for mobile applications. Energy Technol. 6, 487-500. doi: 10.1002/ente.201700517

Martin, A., Agnoletti, M. F., and Brangier, E. (2020). Users in the design of Hydrogen Energy Systems: a systematic review. Int. J. Hydrogen Energy 45, 11889-11900. doi: 10.1016/j.ijhydene.2020.02.163

Orimo, S.-I., Nakamori, Y., Eliseo, J. R., Züttel, A., and Jensen, C. M. (2007). Complex hydrides for hydrogen storage. Chem. Rev. 107, 4111-4132. doi: $10.1021 / \mathrm{cr} 0501846$

Ouyang, L. Z., Chen, K., Jiang, J., Yang, Y. S., and Zhu, M. (2020). Hydrogen storage in light-metal based systems: a review. J. Alloys Compd. 829:54597. doi: 10.1016/j.jallcom.2020.154597 on how to improve the performance of $\mathrm{LiBH}_{4}$-based hydrogen storage materials.

As the Guest Editors of this topic issue, we would like to thank all the authors for their contributions and all the referees for their thoughtful suggestions and insights. We hope this special issue will inspire research and interest in light metal hydrides for hydrogen storage, and that future endeavors will contribute to the realization of a hydrogen economy that is sustainable and environmentally friendly.

\section{AUTHOR CONTRIBUTIONS}

All authors listed have made a substantial, direct and intellectual contribution to the work, and approved it for publication.

\section{ACKNOWLEDGMENTS}

YL acknowledges financial support from the National Key R\&D Program of China grant 2018YFB1502102, the National Natural Science Foundation of China grants 51671172 and U1601212, and the National Youth Top-Notch Talent Support Program. $\mathrm{H}-\mathrm{WL}$ is grateful to the support from the JSPS KAKENHI (grant 18H01738). $\mathrm{ZH}$ acknowledges support under the Australian Research Council's Discovery Projects funding scheme (project number DP170101773).

Schlapbach, L., and Züttel, A. (2001). Hydrogen-storage materials for mobile applications. Nature 414, 353-358. doi: 10.1038/35104634

Schneemann, A., White, J. L., Kang, S. Y., Jeong, S., Wan, L. F., Cho, E. S., et al. (2018). Nanostructured metal hydrides for hydrogen storage. Chem. Rev. 118, 10775-10839. doi: 10.1021/acs.chemrev.8b00313

$\mathrm{Wu}$, H. (2008). Strategies for the improvement of the hydrogen storage properties of metal hydride materials. ChemPhysChem 9, 2157-2162. doi: 10.1002/cphc.200800498

Yu, X. B., Tang, Z. W., Sun, D. L., Ouyang, L. Z., and Zhu, M. (2017). Recent advances and remaining challenges of nanostructured materials for hydrogen storage applications. Prog. Mater. Sci. 88, 1-48. doi: 10.1016/j.pmatsci.2017.03.001

Zhou, H., Wang, X. H., Liu, H. Z., Gao, S. C., and Yan, M. (2019). Improved hydrogen storage properties of $\mathrm{LiBH} 4$ confined with activated charcoal by ball milling. Rare Metals 38, 321-326. doi: 10.1007/s12598-01 8-1067-1

Conflict of Interest: The authors declare that the research was conducted in the absence of any commercial or financial relationships that could be construed as a potential conflict of interest.

Copyright (c) $2020 \mathrm{Liu}, \mathrm{Li}$ and Huang. This is an open-access article distributed under the terms of the Creative Commons Attribution License (CC BY). The use, distribution or reproduction in other forums is permitted, provided the original author(s) and the copyright owner(s) are credited and that the original publication in this journal is cited, in accordance with accepted academic practice. No use, distribution or reproduction is permitted which does not comply with these terms. 